\title{
La constitucionalización de los derechos sociales: puentes entre Brasil y México*
}

The Constitutionalisation of Social Rights: Bridges Between Brazil and Mexico

\section{Gustavo Ferreira Santos**}

\section{RESUMEN}

Este artículo es resultado de una investigación sobre influencias de la constitución mexicana de 1917 en el debate constitucional brasileño. El texto apunta referencias a esta Constitución, pionera en el proceso constituyente de 1934, marco inicial del constitucionalismo social en Brasil. Investiga los registros del trabajo de los constituyentes. Hace análisis de las referencias al texto constitucional mexicano en libros brasileños de derecho constitucional en los primeros años después del proceso constituyente de 1934 y en tiempos recientes. En el movimiento sindical, la influencia de México ha sido fuerte; pero la prensa he presentado una visión negativa del proceso revolucionario.

PALABRAS CLAVE: Constitucionalismo social; constitución; constituyente

\section{ABSTRACT}

The article is the result of a research about influences of the Constitution of the Mexico of 1917 on the Brazilian constitutional debate. The text makes references to this Constitution, pioneering in the constitutional process of 1934, initial framework of the social constitutionalism in Brazil. For this, it investigates the records of the work of the constituents. It analyses references to the Mexican constitutional text in Brazilian constitutional law books in the first years after the constituent process of 1934 and in recent times.

KEY WORDS: Social constitutionalism; constitution; constituent

\footnotetext{
* Artículo recibido el 13 de enero de 2016 y aceptado para su publicación el 22 de febrero de 2016.

** Profesor de Derecho Constitucional en la Universidad Católica de Pernambuco y de la Universidad Federal de Pernambuco, Brasil. (gustavosantos@uol.com.br).
} 


\section{SUMARIO}

\section{Introducción}

2. Los primeros impactos en la política y en la doctrina juridica del derecho constitucional referentes a la Revolución mexicana y la Constitución de 1917

3. México y la primera constitución social brasileña

3.1 La Constituyente de 1933 -1934

3.1.1 El contexto de la Asamblea Nacional Constituyente

3.1.2. La Constitución mexicana en el debate del constituyente brasileño

3.2 La Constitución de 1934

4. El debate constitucional y los impactos de la Constitución de México de 1917

5. Consideraciones finales

6. Bibliografía

\section{Introducción}

México tiene una importancia simbólica en el estudio de los derechos fundamentales por ser el primer país del mundo en haber constitucionalizado derechos sociales. Este pionerismo debe resaltarse, en un momento en el cual se conmemora el centenario de su Constitución. La Constitución mexicana de 1917 representó un giro en su propio concepto material de una constitución, alterando, definitivamente, la relación entre Estado y derechos fundamentales.

Brasil tuvo su primera experiencia de constitución con contenidos sociales en 1934. Se trata de una experiencia constitucional breve. Esta Constitución fue substituida en 1937, con la edición de un nuevo documento. Sin embargo, dejó marcas por su pionerismo en nuestra historia constitucional. Los derechos sociales ya habían sido constitucionalizados en otros países. La constituyente brasileña tenía a su disposición un conjunto de experiencias que podrían ser estudiadas y citadas para justificar el contenido social de su Constitución. Ejercieron una especial influencia en el debate brasileño las constituciones de México de 1917, la de Alemania de 1919 y la de España de 1931.

Brasil y México tienen en común varias características, a pesar de la relativa distancia geográfica. Son dos grandes países de América Latina que enfrentaron problemas políticos y económicos semejantes. Es necesario destacar especialmente el proceso de constitucionalización en el aspecto social en Brasil, e identificar las posibles influencias recibidas de la más antigua experiencia constitucional social. 
En un primer momento, se identifican todas las referencias hechas en México en los anales de la Constituyente de 1933 a 1934. En un segundo momento, serán separadas las citaciones que tienen relación con la constitucionalización del aspecto social. Acto seguido, serán indicadas las repercusiones en el debate constitucional brasileño del pionerismo social en la experiencia constitucional mexicana.

\section{Los primeros impactos en la política y en la doctrina jurídica del derecho constitucional referentes a la Revolución mexicana y la Constitución de 1917}

Las dos primeras décadas del siglo xx están marcadas en Brasil por algunos conflictos sociales y reivindicaciones dirigidas al Estado. El anarcosindicalismo tiene su apogeo especialmente en las grandes ciudades, São Paulo y Rio de Janeiro, que han tenido una fuerte presencia de prole obrera de origen europea, la cual traía consigo tales ideales políticos. En la segunda década, más exactamente en 1922, se fundó el Partido Comunista Brasileño que representa una influencia mayor en la Revolución rusa.

En la prensa sindical de inspiración anarcosindicalista, existieron referencias constantes a la Revolución mexicana. Había un tono de simpatía al movimiento. Periódicos sindicales, como La Bataglia, publicaron materias traducidas del periódico mexicano Regeneración. ${ }^{1}$ Los anarquistas brasileños eran solidarios a los revolucionarios mexicanos y participaban en una verdadera red internacional, donde el diario Regeneración, jugaba un papel importante. ${ }^{2}$

En el año de 1913, hubo un auge sobre las referencias a la Revolución mexicana en el diario $\mathrm{La}$ Voz del Trabajador, editado en Rio de Janeiro, por la Confederación Operaria Brasileña. Las editoriales del periódico "declaraban su apoyo a los rebeldes mexicanos; buscaban explicar la situación política en el país desde un punto de vista de los revolucionarios campesinos; informaban además el envío de una carta-protesta dirigida al presidente de los Estados Unidos contra la detención de líderes del Partido Liberal Mexicano, PLm (Ricardo y Enrique Flores Magón, Anselmo Figueroa y Librado rivera)". ${ }^{3}$

\footnotetext{
1 SousA, FáBı DA SıLVA, "Revolução Mexicana e imprensa operária brasileira: leitura libertária e circulação de idéias", Patrimônio e Memória, vol. 5, No. 1, pp. 175-194, 2009. Disponible en: http://hdl.handle.net/11449/108028

2 Barbosa, Carlos Alberto Sampalo, "A repercussão da Revolução Mexicana na Imprensa Brasileira", Patrimônio e Memória, vol. 2, No. 1, 2006, pp. 60-71, Disponible en http://www.cedap.assis.u"esp.br/patrimonio_e_memoria/ patrimonio_e_memoria_v2.n1/ carlos\%20alberto\%20sampaio\%20barbosa.pdf; SousA, FÁBI0 DA SILvA, "A Revolução Mexicana de Regeneración e as redes libertárias nas Américas", Revista Eletrônica da ANPHLAC, vol. 9, São Paulo, 2010, pp. 1-17. Disponible en: http://revistas.fflch.usp.br/anphlac/article/view/1401

${ }^{3}$ Barbosa, Carlos Alberto Sampalo, "A repercussão da Revolução Mexicana na Imprensa Brasileira", Patrimônio e
} 
En la grande prensa comercial, las noticias sobre la Revolución mexicana eran, generalmente, negativas; la asociaban a la barbarie y la anarquía. Las noticias publicadas en El Estado de São Paulo y Minas Gerais eran provenientes, principalmente, de la agencia de noticias Havas. ${ }^{4}$ En esa época, en el interior de Brasil se vivenciaba una situación política tensa, con conflictos como, por ejemplo, los que el "cangaço" producía en la región del "Sertão". Los diarios aprovechaban las noticias sobre los movimientos campesinos, como el zapatista, para asociar las supuestas "barbaries" que las noticias provenientes de México relataban a los riesgos que Brasil vivía con sus conflictos. ${ }^{5}$ Esta postura de comparación, tomando como referente a México como "una lección para Brasil” fue adoptada tanto en la prensa por los que defendían la represión a las insurgencias, como por los que defendían las mudanzas políticas y económicas en Brasil.

Una interesante postura de la asociación entre lo que sucedía en México y lo que ocurría en Brasil fue la de José Veríssimo, quien escribía en el diario El Imparcial, de Rio de Janeiro. En los primeros años de la Revolución, el articulista elogiaba a México como un ejemplo; llegó a proponer espejarnos con esta nación. Sin embargo, con el tiempo, fue quedándose más cauteloso y, finalmente, crítico. Para Nataly Dias, ${ }^{7}$ la participación popular en la Revolución mexicana "lo asustó y lo hizo mudar completamente de opinión, cuando pasó a descalificar el proceso revolucionario como obra de simples 'bandidos' y a defender la intervención militar estadounidense en el México revolucionario”.

\footnotetext{
Memória, vol. 2, No. 1, 2006, pp. 60-71, Disponible en http://www.cedap.assis.u"esp.br/patrimonio_e_memoria/ patrimonio_e_memoria_v2.n1/ carlos\%20alberto\%20sampaio\%20barbosa.pdf

${ }^{4}$ SouSA, FÁBIO DA SIIVA, "Revolução Mexicana e imprensa operária brasileira: leitura libertária e circulação de idéias", Patrimônio e Memória, vol. 5, No. 1, pp. 175-194, 2009. Disponible en http://hdl.handle.net/11449/108028; DiAS, Natally Vieira, "O Brasil no 'espelho do México': visões da Revolução Mexicana na imprensa brasileira (1910-1914)", Revista Espaço Acadêmico, vol. 10, No. 114, 2010, pp. 37-45. Disponible en: http://www.periodicos.uem.br/ojs/index. php/EspacoAcademico/article/viewFile/11478/6239

${ }^{5}$ Dias, Nataly Vieira, "O Brasil no 'espelho do México': visões da Revolução Mexicana na imprensa brasileira (19101914)", Revista Espaço Acadêmico, vol. 10, No. 114, 2010, pp. 37-45. Disponible en: http://www.periodicos.uem.br/ ojs/index.php/EspacoAcademico/article/viewFile/11478/6239

${ }^{6}$ Dias, Nataly Vieira, "O Brasil no 'espelho do México': visões da Revolução Mexicana na imprensa brasileira (19101914)", Revista Espaço Acadêmico, vol. 10, No. 114, 2010, pp. 37-45. Disponible en: http://www.periodicos.uem.br/ ojs/index.php/EspacoAcademico/article/viewFile/11478/6239

7 Dias, Natally VIelRa, "O Brasil no 'espelho do México': visões da Revolução Mexicana na imprensa brasileira (19101914)", Revista Espaço Acadêmico, vol. 10, No. 114, 2010, pp. 37-45. Disponible en: http://www.periodicos.uem.br/ ojs/index.php/EspacoAcademico/article/viewFile/11478/6239
} 


\section{México y la primera constitución social brasileña}

\subsection{La Constituyente de $1933-1934$}

\subsubsection{El contexto de la Asamblea Nacional Constituyente}

Brasil se independizó de Portugal en 1822, habiendo adoptado, en la Constitución de 1824, un modelo monárquico de gobierno. La Constitución del imperio estaba influenciada por el constitucionalismo inglés y por el constitucionalismo francés de restauración. El periodo de la constitución monárquico fue el más longevo de la historia constitucional del país.

En 1889, un golpe militar destituyó al emperador Pedro II e instauró la República. En su primera constitución republicana, promulgada en 1891, Brasil se adhirió a un modele norte americano de constitucionalismo. Inclusive, absorbió un conjunto de instituciones típicas del modelo norteamericano, como el presidencialismo, la federación y el control judicial de la constitucionalidad. En ese período, conocido como la Primera República (1889-1930), hubo una sucesión de gobiernos oligárquicos, la cual se caracterizó por una dominación de los estados de São Paulo y Minas Gerais.

En 1930, luego de las elecciones presidenciales y antes de tomar el juramento del cargo del vencedor, sucedió una revolución que rompió con la tradición de la primera república y permite ascender al poder Getúlio Vargas, candidato derrotado en las elecciones, que instauró un gobierno fuerte. Los primeros años de posrevolución fueron acentuados por una fuerte inestabilidad, ya que ninguno de los diferentes grupos que hicieron la revolución pudo lograr el comando. ${ }^{8}$ Hay un fuerte clamor en los años que siguen por la reconstitucionalización del país.

Apenas en 1932 fueron convocadas elecciones para una Asamblea Nacional Constituyente. Ocurrió un proceso electoral en 1933. Además de la representación tradicional, el Código Electoral prevé la representación clasista, con representantes electos por empleadores, empleados, profesionales liberales y servidores públicos. ${ }^{9}$

Todavía en 1932, fue creada por el presidente Getúlio Vargas una comisión con varios juristas para proponer un proyecto. En el trabajo de la Comisión ya surgía una necesidad de tratar el nuevo texto constitucional sobre los asuntos

\footnotetext{
${ }^{8}$ Gomes, Angela Maria de Castro, "Confronto e compromisso no processo de constitucionalização (1930-1935)", en História da Civilização Brasileira, tomo 3, vol. 3, 1981.

${ }^{9}$ IglÉsias, Francisco, Trajetória política do Brasil, 1500-1964, São Paulo, Companhia das letras, 1993.
} 
sociales. Luego de la presentación de Carlos Maximiliano para un texto inicial del debate, João Mangabeira expresó que "Todas las constituciones modernas tienen como orientación acabar con las desigualdades sociales. Si la Constitución Brasileña no marcha en la misma dirección, dejará de ser revolucionaria para tornarse reaccionaria”. ${ }^{10}$

Es posible notar, ya en ese instante, una postura que se reflejaría en la Asamblea Nacional Constituyente. La defensa de un determinado tipo de constitución está basada en la comparación de experiencias extranjeras. La Asamblea Nacional Constituyente trajo consigo un conjunto de restricciones provenientes de actos normativos editados por el Gobierno. El Decreto 22.621, de 7 de abril de 1933, el cual convocó la Asamblea Nacional Constituyente, trajo un anexo con su regimiento. Ronaldo Poletti ${ }^{11}$ destaca las restricciones hechas por dicho documento gubernamental, así:

Determinaba el Decreto hasta los pormenores de la instalación y la lectura del proyecto de Constitución remitido por el Gobierno Provisorio (art.15); trataba las enmiendas (art. 17); disponía sobre la Comisión Constitucional incumbida de dar parece sobre el proyecto (art. 19). El presidente de la Asamblea podía recusar el recibimiento de enmiendas al proyecto constitucional (art. 33). Los ministros de estado podían ser convocados, pero tenían el derecho de comparecer y de participar de los debates, siempre que lo entendiesen necesario o cuando fuesen destacados por el Jefe de Gobierno (art 53).

\subsubsection{La Constitución mexicana en el debate del constituyente brasileño}

Los Anales de la Asamblea Constituyente revelan algunas referencias a Mexico. Muchas de estas referencias no abordan directamente la Constitución de 1917. Cuidan los aspectos históricos o políticos más generales. Más de una vez en el debate sobre la relación entre el Estado y la Iglesia fue citada la situación en México. Con mayor precisión respecto al texto constitucional mexicano, los anales de la constituyente registraron referencias a las discusiones sobre varios temas, tales como el presidencialismo, el federalismo y la organización del Legislativo.

Una referencia específica de México que llama la atención, por ser un uso distorsionado del ejemplo, se da cuando el diputado Alfredo da Mata defendió

\footnotetext{
${ }^{10}$ Polettı, Ronaldo, "A Constituição de 1934", Constituições brasileiras, Brasilia, Senado Federal, 2001.

11 Poletti, Ronaldo, "A Constituição de 1934", Constituições brasileiras, Brasilia, Senado Federal, 2001.
} 
el establecimiento del examen médico prenupcial, fundado en argumentos de eugenesia. Para fundamentar que es posible incluir un tema de ese tipo en la Constitución, indicó un conjunto de constituciones que tratan los temas inicialmente ajenos a la disciplina constitucional: la de Suiza, trata de la caza y de la pesca; la de Baviera, regula asuntos religiosos; la de Holanda, trata de las aguas; la de México, regula el petróleo; la de Rumania, habla sobre la propiedad agraria y el subsuelo, los bosques y latifundios; la de Grecia, habla sobre la Iglesia ortodoxa; la de Alemania, prohíbe la usura; la de Checoslovaquia, reconoce el derecho de las minorías religiosas, y la de España, cita los principios sobre la familia. ${ }^{12}$

Es importante destacar que hay más de una referencia a la cuestión de la tierra. México fue visto como ejemplo respecto a la nacionalización de la propiedad de la tierra y a la reforma agraria. Hubo, inclusive, transcripción en los anales de la constituyente del texto del artículo 27 de la Constitución de México.

Respecto a los derechos sociales, tema que se eligió como eje de este trabajo, hay diversas referencias. Hay, sin embargo, referencias más numerosas a la Constitución de Alemania de 1919 y a la de España de 1931. A decir verdad, es un recurso argumentativo común hacer referencia hacia alguna experiencia constitucional extranjera.

Muchas de estas referencias a la constitucionalización de los derechos sociales son genéricas. Hablan de la importancia de constitucionalizar el orden social y los derechos laborales. Citan algunos países que regularon en la constitución un orden económico y social e incluyen en ese rol a México. En ocasiones, en estos casos, el orador quiere justificar un dispositivo que él mismo propone, independientemente de apuntar en las constituciones extranjeras citadas un dispositivo similar. Es en el caso de la defensa a la asistencia jurídica gratuita para los pobres cuando México es nombrado como ejemplo de reconocimiento de deberes para con los pobres. ${ }^{13}$

Dentro de las referencias genéricas, destacamos que una de ellas fue escogida por el diputado Morales Leme, en sesión de votación del dispositivo que pretendía abordar la libertad de industria y que dejó claro cómo él veía la Constitución mexicana. El diputado pidió destaque, considerando que el dispositivo suprimía la libertad cuando decía que ella estaba garantizada si "no se perjudicara la salubridad pública y la defensa nacional". Citó las constituciones de Alemania, España y México para decir que "las constituciones

\footnotetext{
${ }^{12}$ Anais da Assembleia Nacional Constituinte, vol. Ix, Rio de Janeiro, Imprensa Nacional, 1936, p. 182.

${ }^{13}$ Anais da Assembleia Nacional Constituinte, vol. XVIII, Rio de Janeiro, Imprensa Nacional, 1936, p. 256.
} 
modernas, incluso las de confección más acentuadamente socialistas, garantizan la libertad de industria". ${ }^{14}$

Hay, además, algunas referencias muy específicas, especialmente a las que se refieren a los derechos laborales. Inclusive, como he dicho antes, hay citaciones literales de algunos dispositivos de la Constitución mexicana. En el debate sobre el salario mínimo, la Constitución mexicana se citó para justificar su adopción. El texto final, sin embargo, quedó algo poco parecido al modelo mexicano, ya que dijo apenas que la legislación laboral necesitaba observar "El salario mínimo, capaz de satisfacer, conforme las condiciones de cada región, a las necesidades normales del trabajador". Como se puede ver, un texto muy simple en contraste con el mexicano, ya que deja de citar las necesidades específicamente.

Además del salario, el artículo 123, X, de la Constitución mexicana se citó para justificar la inserción de una norma en la Constitución que protegiese al trabajador, garantizando que su salario fuera remunerado en moneda corriente. El dispositivo no fue, al final, implantado en la Constitución.

México también se citó en el debate sobre la jornada diaria máxima de trabajo. Al proponer una enmienda, la cual no fue aprobada, para fijar el límite máximo de seis horas, el país mexicano se citó dentro del grupo de países en los cuales esto sería un "problema social vencido". Al final, se fijó una jornada máxima de ocho horas, tal como lo estipuló México.

\subsection{La Constitución de 1934}

El movimiento brasileño que llevó a Getúlio Vargas al poder no puede compararse con la Revolución mexicana. El primerio es, fundamentalmente, un movimiento oligárquico; el segundo, a pesar de la participación de los sectores de la elite económica, tiene una base popular fuerte. Tampoco son comparables los textos constitucionales que resultaron de dos movimientos. Montenegro Bentes resume el contraste entre los dos movimientos y, consecuentemente, las dos Constituciones: "mientras la Constitución brasileña de 1934 nace con el desdoblamiento posterior de una revolución oligárquica, la Constitución mexicana de 1917 nace a partir de una guerra civil con amplia participación popular". ${ }^{15}$

La Constitución brasileña de 1934 es, como una constitución del constitucionalismo social, tímida al contrastarla con el texto mexicano. En un estudio comparativo entre las constituciones de Brasil y México, específicamente re-

\footnotetext{
${ }^{14}$ Anais da Assembleia Nacional Constituinte, vol. xxı, Rio de Janeiro, Imprensa Nacional, 1936, p. 125.

${ }^{15}$ Bentes, Fernando, "Os Direitos do Trabalho nas Constituições do Brasil de 1934 e do México de 1917", Direito, Estado e Sociedade, vol. 30, pp. 33-51, Rio de Janeiro, 2007.
} 
feridas a la consagración de derechos laborales, Montenegro Bentes concluyó que ambos textos son muy diferentes. El texto mexicano tiene un rol mayor de derechos, y los aborda con mayor concreción. El texto brasileño es mucho más programático; deja de especificar muchos de los derechos que trata.

A pesar de su carácter innovador, la Constitución brasileña de 1934, al haber tenido una innegable importancia histórica, no fue un estatuto constitucional con una larga vigencia. Fue suplantada en 1937, cuando Getúlio Vargas otorgó una nueva Constitución, estableciendo lo que sus partidarios llamaron de "Estado Nuevo", régimen y Constitución con características nítidamente autoritarias. Getúlio, quien estaba presidiendo Brasil desde 1930, sin haber sido elegido popularmente, fue legitimado por la Constitución de 1934. Esta última previó en las "disposiciones transitorias" que la Asamblea Nacional Constituyente eligiera un presidente un día posterior a la promulgación de la Constitución.

\section{El debate constitucional y los impactos de la Constitución de México de 1917}

La Constitución de 1934 inaugura, en Brasil, una tradición de Constituciones que trajeron parámetros para la economía e hicieron referencia a los aspectos sociales. Ninguna constitución brasileña, a partir de esa experiencia, trató la relación Estado-sociedad a la manera liberal de las dos constituciones anteriores.

Antes, bajo la Constitución de 1981, de matiz liberal, no había prácticamente referencias al régimen constitucional mexicano en los libros didácticos brasileños de derecho constitucional. Leemos textos de Rodrigo Octavio y Vianna, ${ }^{16}$ Silva Marques ${ }^{17}$ y Guedes Alcoforado, ${ }^{18}$ publicados entre 1919 y 1927, sin encontrar referencias al sistema constitucional de México.

En el libro donde se discutía la elaboración de la Constitución de 1934, João Mangabeira, relator del Anteproyecto de Constitución presentado por el gobierno, aborda la protección de las riquezas del subsuelo y cita a México como ejemplo. Lo más interesante de la referencia es que, en un capítulo, abre el ítem sobre "México y los Estados Unidos". Apenas informa que México hace diferente lo que el sustitutivo discutido en la Constituyente brasileña estaba realizando, para luego hablar de manera extensa sólo de los Estados Unidos. ${ }^{19}$

\footnotetext{
${ }^{16}$ Octavio, Rodrigo Y Vianna, Paulo, Elementos de direito publico e constitucional brasileiro, Rio de Janeiro, F Briguiet, 1919; Octavio, Rodrigo y Vianna, Paulo, Elementos de direito publico e constitucional brasileiro, Rio de Janeiro, F Briguiet, 1927.

${ }^{17}$ Maroues, Silva, Elementos de direito público e constitucional, Rio de Janeiro, Benjamin de Aguila, 1919.

${ }_{18}$ Guedes Alcoforado, Luiz Sebastião, Direito internacional público: (a sociedade dos estados): Direito público e constitucional (o estado federal), Recife, Imprensa industrial, 1922.

${ }^{19}$ Mangabelra, João, Em nome da constituição, São Paulo, Companhia Editora Nacional, 1934.
} 
Pedro Calmón, ${ }^{20}$ en su Curso de derecho constitucional, ya bajo la Constitución de 1946, presenta una nota al pie de página donde se pregunta cuáles son las influencias que Brasil sufrió en la Constitución de 1934. En respuesta, le atribuye a la Alemania de Weimar la influencia sobre el orden económico; además, hace una referencia al amparo de la de México como influencia para la creación de la acción del juicio de amparo (Mandado de Segurança en Brasil).

Curiosamente, en uno de los más importantes libros brasileños en el que se discute la transición del Estado liberal al Estado social, no se aborda la Revolución mexicana ni la Constitución de 1917. El clásico Del Estado liberal al Estado social, de Paulo Bonavides, ${ }^{21}$ enfatiza las características del liberalismo político y de la intervención del Estado. Se reserva un amplio espacio para discutir las concepciones políticas socialistas.

En una conferencia proferida en México, en 2006, donde se trató el tema del constitucionalismo social, Paulo Bonavides, ${ }^{22}$ hizo una digresión histórica. Resaltó el pionerismo de la Constitución mexicana de 1917. Reconoce, inclusive, un "contenido cualitativo y cuantitativo" en la Constitución mexicana de 1917 que excede al de la Constitución de Weimar. Sin embargo, dice haber sido la Constitución alemana una irradiación para otras constituciones, influenciando sus contenidos. En el mismo artículo, al referirse a la Constitución brasileña de 1934, él mismo registra que trató la Constitución brasileña de derechos sociales sobre lo que propusieron las constituciones de México y de Alemania.

Un estudio sobre la formación histórica de los derechos humanos bastante recomendado en los cursos de Derecho, de autoría de Fabio Konder Comparato, ${ }^{23}$ profesor de la Universidad de São Paulo, reserva todo un capítulo a la Constitución de México de 1917. El libro contextualiza históricamente la Constitución; informa sobre el impacto del anarcosindicalismo, especialmente al pensamiento de Bakunin, sobre los intelectuales que se oponían a la dictadura de Porfirio Díaz, y resalta las posteriores confusiones, después de la creación del Partido Revolucionario Institucional, en 1929. El texto destaca el pionerismo mexicano en la constitucionalizacion de los derechos laborales, apenas constitucionalizados en Europa después de la Primera Guerra Mundial y declarados internacionalmente con la creación de la Organización Internacional del Trabajo, en 1919. El libro hace una diferencia relevante entre los "derechos

\footnotetext{
${ }^{20}$ Calmon, Pedro, Curso de Direito Constitucional Brasileiro: Constituição de 46, Rio de Janeiro, Freitas Bastos, 1947.

${ }^{21}$ Bonavides, Paulo, Do Estado Liberal ao Estado Social, São Paulo, Malheiros, 2009.

22 Bonavides, Paulo, "Constitucionalismo social e democracia participativa", Ponencia en Congreso Constitucional de Derecho Constitucional, unam, Mexico, 2006. Disponible en: http://www.juridicas.unam.mx/sisjur/constit/pdf/6-234s. pdf

${ }^{23}$ Comparato, Fábio Konder, A Afirmação Histórica dos Direitos Humanos, São Paulo, Saraiva, 2008.
} 
del pueblo trabajador y operario", declarados después de la Revolución rusa y los derechos de los trabajadores declarados en la Constitución mexicana: "el pueblo mexicano no está reducido apenas a la clase trabajadora”.

También es rápida la referencia a la Constitución de México en el Curso de derecho constitucional positivo" de José Afonso da Silva, ${ }^{24}$ profesor de Derecho Constitucional de la Universidad de São Paulo. En el libro, editado desde 1976, el autor reconoce que el orden social está sistematizado en las Constituciones, a partir de la Constitución mexicana de 1917. Hace lo mismo respecto al orden económico, cuando se refiere en la introducción del tema del constitucionalismo brasileño, en la Constitución de 1934, al decir que ha sido influenciada por la Constitución de Weimar.

En el Curso de derecho constitucional de André Ramos Tavares ${ }^{25}$ la Constitución mexicana hace referencia en una nota de pie de página, cuando dice que, en ella, "proclamados por la primera vez". Posteriormente, hace una resalva en la cual indica que la Constitución alemana de Weimar "contribuyó para popularizar y extender los derechos sociales”. En un manual de Derecho constitucional económico, el mismo autor trata en tres páginas a la Constitución mexicana de 1917; reconoce su pionerismo, pero, cuando aborda a la Constitución brasileña de 1934 apenas resalta la influencia de la Constitución de Weimar.

Algunos autores hacen referencia a la "Declaración de Derechos del Pueblo Trabajador y Explotado", en Rusia, de 1918. Pinto Ferreira ${ }^{26}$ llegó a decir que "esa fue la primera declaración más importante en el sentido de las "grandes declaraciones económicas" del siglo xx.

Manoel Gonçalves Ferreira Filho ${ }^{27}$ también hace referencia a México, en su Curso de derecho constitucional. El autor -defensor de una visión económica liberal y conservador en la política- minimiza la importancia de la Constitución mexicana en dos momentos: a) cuando aborda la "doctrina de los derechos fundamentales y su evolución" y b) cuando trata la "constitución económica”. Sobre los derechos sociales, enfatiza la importancia de las constituciones alemana, de 1919, y española, de 1931. Dice además: "con menor repercusión que ellas y caracterizada por un nacionalismo exacerbado está la Constitución mexicana de 1917, tal vez la primera a incorporar esas nuevas ideas”.

Sobre la constitución económica, más de una vez reduce la importancia de la Constitución mexicana al expresar que la Constitución de Weimar "fijó el modelo", que "hay quien conteste esta primacía, apuntando la anterioridad de

\footnotetext{
${ }^{24}$ Silva, Jose Afonso, Curso de Direito Constitucional Positivo, São Paulo, Malheiros, 2006.

${ }^{25}$ Tavares, Andre Ramos, Curso de Direito Constitucional, São Paulo, Saraiva, 2014.

${ }^{26}$ Ferrelra, Pinto, Curso de direito constitucional, São Paulo, Saraiva, 1998.

${ }^{27}$ Ferrelra Filho, Manoel Gonçalves, Curso de direito constitucional, São Paulo, Saraiva, 2012.
} 
la Constitución mexicana de 1917”. Él mismo reconoce que la Constitución mexicana anticipa derechos sociales y reforma agraria, sin embargo, no trajo un tratamiento sistemático de la economía. Finalmente, termina hablando de la Constitución de Weimar: "fie ella y no la mexicana que sirvió de inspiración, y fue copiada, a veces, por las Constituciones de Europa Central y báltica de España (1931), y por la brasileña de 1934”.

Es importante destacar que no es exclusividad del debate constitucional de Brasil, la práctica de dar énfasis a la importancia de la Constitución de Weimar de 1919, cuando aborda el surgimiento en las constituciones de los derechos sociales. Varios son los factores que pueden explicar esa opción. María Claudia Bucchianeri Pinheiro ${ }^{28}$ arriesga al decir:

Esa preponderancia de Weimar sobre la Constitución mexicana, cronológicamente anterior, no sólo se debe a la circunstancia de tratarse de una constitución promulgada en suelo europeo (y no en lejanas tierras americanas), mas, también, a la naturaleza más abstracta y menos "local" de sus prescripciones y a la fuerza, autoridad y vivacidad de la doctrina constitucional alemana de la época, que hizo recorrer por el mundo las victorias y las vicisitudes del nuevo texto republicano de 1919.

\section{Consideraciones finales}

La clara influencia de la Constitución mexicana de 1917 sobre la primera Constitución social brasileña, adoptada en 1934, hizo permanecer en algunos libros didácticos del derecho constitucional brasileño la referencia de aquella constitución. En tales libros didácticos, esta referencia está marcada por la superficialidad. No es posible, a partir de tales libros, comprender todo aquello en lo que la Constitución mexicana fue innovadora y, consecuentemente, el alcance de la influencia que ejerció sobre la Constitución brasileña.

Es necesario profundizar el estudio de la relación entre la primera experiencia del constitucionalismo social en Brasil y la Constitución mexicana de 1917. Todavía son muy superficiales las relaciones hechas en los estudios publicados en Brasil.

\footnotetext{
${ }^{28}$ Pinheiro, Maria Claudia Bucchianerl, "A Constituição de Weimar e os direitos fundamentais sociais: A preponderância da Constituição da República Alemã de 1919 na inauguração do constitucionalismo social à luz da Constituição Mexicana de 1917", Revista de Informação Legislativa, año 43, No. 169, Brasilia, Senado Federal, 2006.
} 
Un rápido vistazo sobre la Asamblea Constituyente de 1933-1934 revela que, a pesar de las frecuentes referencias a las constituciones de Alemania, de 1919, y la de España, de 1931, los constituyentes discutieron propuestas tomando en cuenta el ejemplo mexicano. Como era de esperarse, esas referencias a los dispositivos constitucionales de México están principalmente en los debates sobre la constitucionalización de los aspectos sociales.

Es posible, sin embargo, extraer algunas conclusiones sobre el pequeño número de referencias a la Constitución mexicana en los textos de derecho constitucional del periodo. Cuando se considera la información de la prensa sindical, varias fueron las citaciones de la Revolución mexicana. Consideramos la hipótesis en la cual no se reflejó ese conocimiento en la Constituyente por ella ser muy restricta a una elite económica, representada por personas que tenían una formación jurídica y social mucho más direccionada a la observación de Europa. Como se ve, fueron muy comunes, en los debates y en la literatura jurídico-constitucional, las referencias a la Constitución de Weimar.

También es importante considerar que la cobertura de la prensa brasileña sobre los acontecimientos en México fue, por regla general, negativa. La asociación entre la Revolución mexicana y la anarquía tal vez reduzca la fuerza que el ejemplo tiene en la argumentación política.

El Estado social todavía es, en Brasil, un ente en construcción. Apenas después de la Constitución de 1988 es posible ver políticas públicas encaminadas a la universalización del acceso a los derechos prestacionales. Los derechos del trabajador tienen, aún, una fuerte marca de la década de los treinta, cuando fueron introducidos en el país. El estudio histórico comparativo promete lanzar importantes luces sobre el contexto actual.

\section{Bibliografía}

Anais da Assembleia Nacional Constituinte, vol. Ix, Rio de Janeiro, Imprensa Nacional, 1936.

Anais da Assembleia Nacional Constituinte, vol. xvIII, Rio de Janeiro, Imprensa Nacional, 1936.

Anais da Assembleia Nacional Constituinte, vol. xxI, Rio de Janeiro, Imprensa Nacional, 1936.

Barbosa, Carlos Alberto Sampaio, "A repercussão da Revolução Mexicana na Imprensa Brasileira”, Patrimônio e Memória, vol. 2, No. 1, 2006, pp. 6071, Disponible en http://www.cedap.assis.u"esp.br/patrimonio_e_memoria/ patrimonio_e_memoria_v2.n1/ carlos\%20alberto\%20sampaio\%20barbosa. pdf 
Bentes, Fernando, "Os Direitos do Trabalho nas Constituições do Brasil de 1934 e do México de 1917”, Direito, Estado e Sociedade , vol. 30, pp. 33-51, Rio de Janeiro, 2007.

Bonavides, Paulo, "Constitucionalismo social e democracia participativa", $P o-$ nencia en Congreso Constitucional de Derecho Constitucional, unAM, Mexico, 2006. Disponible en: http://www.juridicas.unam.mx/sisjur/constit/pdf/6234s.pdf

Bonavides, Paulo, Do Estado Liberal ao Estado Social, São Paulo, Malheiros, 2009.

Calmon, Pedro, Curso de Direito Constitucional Brasileiro: Constituição de 46, Rio de Janeiro, Freitas Bastos, 1947.

Comparato, Fábio Konder, A Afirmação Histórica dos Direitos Humanos, São Paulo, Saraiva, 2008.

Dias, Natally Vieira, “0 Brasil no 'espelho do México': visões da Revolução Mexicana na imprensa brasileira (1910-1914)", Revista Espaço Acadêmico, vol. 10, No. 114, 2010, pp. 37-45. Disponible en: http://www.periodicos. uem.br/ojs/index.php/EspacoAcademico/article/viewFile/11478/6239

Ferreira, Pinto, Curso de direito constitucional, São Paulo, Saraiva, 1998.

Ferreira Filho, Manoel Gonçalves, Curso de direito constitucional, São Paulo, Saraiva, 2012.

Guedes Alcoforado, Luiz Sebastião, Direito internacional público: (a sociedade dos estados): Direito público e constitucional (o estado federal), Recife, Imprensa industrial, 1922.

IglÉsias, Francisco, Trajetória politica do Brasil, 1500-1964, São Paulo, Companhia das letras, 1993.

Mangabeira, João, Em nome da constituição, São Paulo, Companhia Editora Nacional, 1934.

Marques, Silva, Elementos de direito público e constitucional, Rio de Janeiro, Benjamin de Aguila, 1919.

Octavio, Rodrigo y Vianna, Paulo, Elementos de direito publico e constitucional brasileiro, Rio de Janeiro, F Briguiet, 1919.

Octavio, Rodrigo y Vianna, Paulo, Elementos de direito publico e constitucional brasileiro, Rio de Janeiro, F Briguiet, 1927.

Pinheiro, Maria Claudia Bucchianeri, "A Constituição de Weimar e os direitos fundamentais sociais: A preponderância da Constituição da República Alemã de 1919 na inauguração do constitucionalismo social à luz da Constituição Mexicana de 1917”, Revista de Informação Legislativa, año 43, No. 169, Brasilia, Senado Federal, 2006.

Poletti, Ronaldo, “A Constituição de 1934”, Constituições brasileiras, Brasília, Senado Federal, 2001. 
Silva, Jose Afonso, Curso de Direito Constitucional Positivo, São Paulo, Malheiros, 2006.

SousA, FÁBIo DA SILVA, "Revolução Mexicana e imprensa operária brasileira: leitura libertária e circulação de idéias”, Patrimônio e Memória, vol. 5, No. 1, pp. 175-194, 2009. Disponible en http://hdl.handle.net/11449/108028 Sousa, FÁbio da SiLva, “A Revolução Mexicana de Regeneración e as redes libertárias nas Américas”, Revista Eletrônica da ANPHLAC, vol. 9, São Paulo, 2010, pp. 1-17. Disponible en: http://revistas.fflch.usp.br/anphlac/article/ view/1401

Tavares, Andre Ramos, Curso de Direito Constitucional, São Paulo, Saraiva, 2014. 